\title{
P282: Health care exposure prevention of tuberculosis by successful implementation of employee safety policy- our experience
}

\author{
M Sri Ratnamani, R Rao \\ From 2nd International Conference on Prevention and Infection Control (ICPIC 2013) \\ Geneva, Switzerland. 25-28 June 2013
}

\section{Introduction}

India accounts for one-fifth of the global Tuberculosis (TB) incident cases. It is estimated that annually around 330,000 Indians die due to TB.[1] The risk of exposure to Health care workers $(\mathrm{HCW})$ is often overlooked and the hospitals also underplay it. In one of the data published in Lung India 11.2 new cases per 1000 personyears of exposure was reported.[2,3] It is an important challenge everywhere, particularly in low and low to middle income countries. [4]

\section{Objectives}

A TB infection control plan that outlines a protocol for the prompt recognition, separation and investigation for suspected or confirmed TB disease was formulated as part of employee safety policy.

\section{Methods}

Our TB infection control program was based on a three-level hierarchy of control measures based on CDC recommendations 2012. Triage of Suspected TB patients on hospital admission was strictly implemented. We used smear-negative algorithms. Structural modifications- Emergency department was provided with a negative pressure room to keep these patients. Behavioral change - Till the patient is proved negative, the staff attending the patient wear N95 mask to reduce the risk for exposure.

\section{Results}

Before implementation open TB cases admitted annually without screening were 15, 14, and 15 in 2007, 2008 and 2009 respectively and after Implementation 5,0,2 in 2010,2011 and 2012 respectively.

\section{Conclusion}

Implementation of policies to prevent exposure of health care workers to Tuberculosis is imperative to prevent Nosocomial TB Infection. Through a effective employee safety policy and a active Infection Control team, nosocomial TB spread can be prevented.

\section{Competing interests}

None declared

Published: 20 June 2013

\section{References}

1. WHO Policy on TB Infection Control in Health -care Facilities, Congregate Settings and Households. Geneva; WHO 2009.

2. Aggarwal AN: Tuberculosis transmission at healthcare facilities in India. Lung India 2009, 26:33-4.

3. Prevention of hospital-acquired infections WHO Department of Communicable Disease, Surveillance and Response. , 2.

4. Robert J'erome, Affolabi D, Awokou F, Nolna D, Manouan B, Acho Y, Gninafon M, Terbucq A, et al: Assessment of organizational Measures to prevent nosocomial Tuberculosis in health facilities of 4 sub-saharan countries in 2010. Infect Control Hosp Epidemiology 2013, 34(2):190-194.

doi:10.1186/2047-2994-2-S1-P282

Cite this article as: Sri Ratnamani and Rao: P282: Health care exposure prevention of tuberculosis by successful implementation of employee safety policy- our experience. Antimicrobial Resistance and Infection Control 2013 2(Suppl 1):P282

Microbiology, apollo hospitals, Hyderabad, India

(c) 2013 Sri Ratnamani and Rao; licensee BioMed Central Ltd. This is an Open Access article distributed under the terms of the Creative 